SCIENTIFIC REPORT

\title{
Optical coherence tomography analysis of axonal loss in band atrophy of the optic nerve
}

\author{
M L R Monteiro, B C Leal, A A M Rosa, M D Bronstein
}

Br J Ophthalmol 2004;88:896-899. doi: 10.1136/bjo.2003.038489

\begin{abstract}
Aims: To measure axonal loss in patients with band atrophy of the optic nerve caused by optic chiasm compression using optical coherence tomography and to evaluate its ability in identifying this pattern of retinal nerve fibre layer (RNFL) loss. Methods: Twenty eyes from 16 consecutive patients with band atrophy of the optic nerve and permanent temporal hemianopia due to chiasmal compression, and 20 eyes from an age and sex matched control group of 16 healthy individuals, were studied prospectively. All patients were submitted to an ophthalmic examination including perimetry and evaluation of the RNFL using optical coherence tomography. Mean RNFL thickness around the optic disc was compared between the two groups.

Results: The mean (SD) peripapillary RNFL thickness of eyes with band atrophy was 101.00 (9.89) $\mu \mathrm{m}, 62.21$ (12.71) $\mu \mathrm{m}, 104.89(12.60) \mu \mathrm{m}$, and 50.13 (16.88) $\mu \mathrm{m}$ in the superior, temporal, inferior, and nasal regions, respectively. The total RNFL mean was $79.94(7.17) \mu \mathrm{m}$. In the control group, the corresponding values were 140.10 (16.06) $\mu \mathrm{m}, 86.50$ (12.17) $\mu \mathrm{m}, 144.60$ (15.70) $\mu \mathrm{m}$, and $97.94(16.02) \mu \mathrm{m}$. The total RNFL mean was 117.72 (9.53) $\mu \mathrm{m}$. The measurements were significantly different between the two groups. Measurements in each of twelve $30^{\circ}$ divisions provided by the equipment also showed significantly different values between eyes with band atrophy and normal controls.

Conclusions: Optical coherence tomography was able to identify axonal loss in all four quadrants as well as in each of the twelve $30^{\circ}$ segments of the disc. Thus, it seems to be a promising instrument in the diagnosis and follow up of neuroophthalmic conditions responsible for RNFL loss, even if predominantly in the nasal and temporal areas of the optic disc.
\end{abstract}

O ptical coherence tomography (OCT) is a non-invasive technique for the acquisition of cross sectional images of retinal structures from which estimates of the thickness of retinal layers can be made. ${ }^{1}$ The ability of OCT to provide quantitative and reproducible measurements of the retinal nerve fibre layer (RNFL) has been shown in experimental and clinical studies. ${ }^{2-6}$ Most of the studies have been performed in patients with glaucoma, ${ }^{7-11}$ a condition in which RNFL loss usually does not follow a specific pattern and, in most cases, is difficult to predict accurately by clinical examination.

The pattern of RNFL loss in patients with optic chiasm compression may represent a model to evaluate the ability of any instrument to measure RNFL loss in the nasal and temporal regions of the optic disc. In patients with extensive mid-chiasmal lesions and showing severe bitemporal hemianopia with preserved nasal field, the crossed nerve fibres are lost with preservation of the uncrossed fibres, which originate in the temporal hemiretina and penetrate the optic nerve through the superior and inferior arcuate fibre bundles. Therefore, RNFL loss occurs predominantly on the nasal and temporal side of the optic disc. Such a pattern may be identified upon ophthalmoscopy as band atrophy (BA) of the RNFL and is an important clinical sign in patients with chiasmal compression. ${ }^{12}{ }^{13}$ We recently evaluated the ability of scanning laser polarimetry (SLP) in the assessment of the RNFL of 19 eyes with BA from chiasmal lesions. ${ }^{14}$ Our study revealed poor sensitivity of SLP to identify RNFL loss in the nasal and temporal areas of the optic disc, indicating that erroneous interpretations are possible when using SLP in the evaluation of optic nerve diseases causing RNFL loss predominantly in these areas. We therefore performed a prospective study using OCT in patients with severe temporal hemianopia and BA of the optic nerve, in order to evaluate its ability to identify this pattern of RNFL loss.

\section{METHODS}

Between June 2002 and August 2003, 20 eyes from 16 patients with temporal hemianopia from chiasmal compression, and 20 eyes from 16 normal age and sex matched controls were studied. All patients had stable visual field (VF) defects and visual acuity (VA) for at least one year and had already been submitted to previous treatment of the suprasellar lesion prior to study entry. The patients underwent a complete ophthalmologic examination including VF evaluation.

Visual field testing was performed using the Goldmann perimeter. The V-4-e, I-4-e, I-3-e, I-2-e, and I-1-e stimuli were used to draw the isopters. Patients were also submitted to standard automated perimetry (Humphrey, 24-2 full threshold test). Visual field and OCT examinations were performed on the same day or within a maximum period of 2 weeks.

The inclusion criteria were: best corrected VA of 20/30 or better in the study eye; complete temporal hemianopia on Humphrey perimetry and complete or almost complete temporal hemianopia on Goldmann perimetry; nasal hemifield within normal limits; spherical and cylinder refraction within \pm 3 dioptres; intraocular pressure less than $22 \mathrm{~mm} \mathrm{Hg}$, and reliable VF. Patients with clinical signs of glaucoma were excluded. Normal subjects were composed of healthy volunteers recruited from hospital staff members, with a normal ophthalmic examination including Humphrey perimetry.

OCT was performed as described elsewhere. ${ }^{2}{ }^{15}$ Circular scans were obtained with a diameter of $3.4 \mathrm{~mm}$ centred on the optic disk. The scan was initiated at clock dial 9:00 and proceeded clockwise. Each scan consisted of 100 evenly

Abbreviations: BA, band atrophy; OCT, optical coherence tomography; RNFL, retinal nerve fibre layer; SLP, scanning laser polarimetry; VA, visual acuity; VF, visual field. 
distributed transverse A scans along the circumference with an acquisition time of 1 second.

Six circular, properly aligned scans were taken in each eye and the three best quality were chosen for analysis. The mean RNFL thickness values were automatically calculated globally and separately for the superior, inferior, temporal, and nasal quadrants (90 degrees each) and for the twelve $30^{\circ}$ segments using OCT software version A5 (Humphrey-Zeiss Medical Systems, San Leandro, CA, USA) (fig 1).

Three different parameters were employed for comparison between the two groups. The first was the mean RNFL thickness of the entire circumference of the optic disk. The second parameter was quadrant thickness of RNFL. The third was segmental thickness for each of the twelve $30^{\circ}$ segments, indicated as clock hours. RNFL measurements were averaged using data from each of the three scans of both of eyes with BA as well as from normal controls. Values were compared using Student's $t$ test; $p$ values of less than 0.05 were considered significant.

Left eyes were considered to be mirror images of right eyes. Therefore, when indicating the $30^{\circ}$ segments as clock hours in table 1 , we considered the hours from 12:00 to 6:00 as nasal hours, and those from 6:00 to 12:00 as temporal hours.

\section{RESULTS}

A total of 20 eyes with temporal hemianopia and 20 control eyes were studied. Data concerning age, sex, type of tumour, VA, and VF can be found in table 2 . The mean age and standard deviation (SD) was 42.3 (15.7) years, range 18-72, in the study group and 42.9 (13.3) years, range $23-67$, in the control group $(\mathrm{p}=0.9$; Student's $t$ test $)$. Eight eyes had complete temporal hemianopia, and the others had almost complete hemianopia with only a small inferior temporal remaining of field with $\mathrm{I} / 3 \mathrm{e}, \mathrm{I} / 4 \mathrm{e}$, or $\mathrm{V} / 4 \mathrm{e}$ target. All eyes with BA revealed complete temporal hemianopia on Humphrey perimetry. Fundoscopic examination revealed BA of the optic disc and RNFL in all 20 eyes with temporal hemianopia.

Table 1 summarises RNFL thickness values in all parameters measured by OCT. The mean (SD) RNFL thickness was 79.94 (7.17) $\mu \mathrm{m}$ in eyes with BA. In these eyes the mean (SD) peripapillary RNFL thickness was 101.00 (9.89) $\mu \mathrm{m}$, $62.21(12.71) \mu \mathrm{m}, 104.89(12.60) \mu \mathrm{m}$, and 50.13 (16.88) $\mu \mathrm{m}$ in the superior, temporal, inferior, and nasal quadrants, respectively. In the control group, the RNFL thickness
Table 1 Mean values (standard deviation) of retinal nerve fibre layer thickness $(\mu \mathrm{m})$ in each segment for the 20 control eyes and 20 eyes with band atrophy

\begin{tabular}{lccc} 
& $\begin{array}{l}\text { Band atrophy } \\
(\mathbf{n}=\mathbf{2 0})\end{array}$ & Controls $(\mathbf{n = 2 0 )}$ & $\mathbf{p ~ V a l u { } ^ { * }}$ \\
\hline Total average & $79.94(7.17)$ & $117.72(9.53)$ & $<0.001$ \\
RNFL quadrants & & & \\
$\quad$ Superior & $101.00(9.89)$ & $140.10(16.06)$ & $<0.001$ \\
Temporal & $62.21(12.71)$ & $86.50(12.17)$ & $<0.001$ \\
Inferior & $104.89(12.60)$ & $144.60(15.70)$ & $<0.001$ \\
Nasal & $50.13(16.88)$ & $97.94(16.02)$ & $<0.001$ \\
Clock hours & & & \\
12 & $110.05(19.56)$ & $143.50(20.33)$ & $<0.001$ \\
11 & $112.01(22.17)$ & $142.00(22.52)$ & $<0.001$ \\
10 & $72.24(13.82)$ & $99.84(15.54)$ & $<0.001$ \\
9 (temporal) & $50.61(18.81)$ & $76.32(13.74)$ & $<0.001$ \\
8 & $61.94(20.31)$ & $83.59(11.64)$ & $<0.001$ \\
7 & $112.49(27.55)$ & $137.07(26.38)$ & 0.006 \\
6 & $117.01(24.12)$ & $160.55(21.25)$ & $<0.001$ \\
5 & $80.81(31.97)$ & $134.42(17.42)$ & $<0.001$ \\
4 & $48.09(22.18)$ & $97.62(18.43)$ & $<0.001$ \\
3 (nasal) & $40.15(20.23)$ & $88.02(18.27)$ & $<0.001$ \\
2 & $62.34(20.29)$ & $110.75(19.08)$ & $<0.001$ \\
1 & $78.54(14.14)$ & $133.02(18.40)$ & $<0.001$ \\
\hline *Student's $t$ test. & & & \\
& & & \\
\hline
\end{tabular}

measured $140.10 \quad(16.06) \mu \mathrm{m}, 86.50 \quad(12.17) \mu \mathrm{m}, \quad 144.60$ (15.70) $\mu \mathrm{m}$, and 97.94 (16.02) $\mu \mathrm{m}$ in the superior, temporal, inferior, and nasal quadrants, respectively. The global RNFL mean was $117.72(9.53) \mu \mathrm{m}$. Values were found to be significantly lower in eyes with BA (table 1 , fig 2 ). The RNFL thickness in each of the twelve $30^{\circ}$ segments in eyes with BA as well as in normal controls is shown in table 1 and fig 3. Values were significantly different in each segment of eyes with BA compared with normal eyes.

\section{DISCUSSION}

Accurate evaluation of RNFL loss is extremely important in glaucoma as well as in many neuro-ophthalmological conditions. After the initial observation by Hoyt and Newman ${ }^{16}$ in 1972 using direct ophthalmoscopy, numerous studies have emphasised its clinical importance. Although several non-invasive techniques have been used to assess the RNFL, it is still unclear whether they effectively measure the
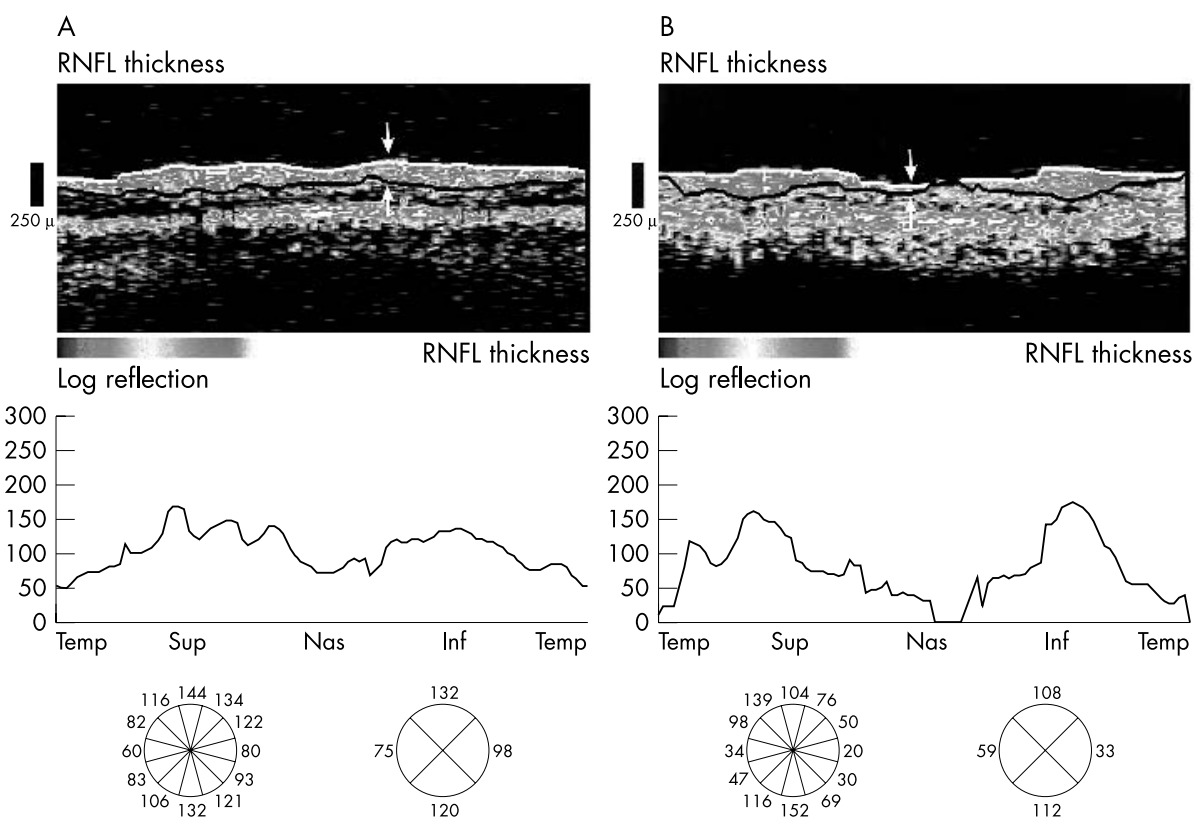

Figure 1 Representative optical coherence tomography (OCT) retinal nerve fibre layer (RNFL) scan results from a normal subject (A) and a patient with band atrophy (B). The arrows delineate the RNFL. 


\begin{tabular}{|c|c|c|c|c|c|c|}
\hline Patient & Sex & Age & Eye & VA & Diagnosis & Visual field \\
\hline 1 & $M$ & 43 & $\mathrm{LE}$ & $20 / 20$ & $\begin{array}{l}\text { Craniophary- } \\
\text { ngeoma }\end{array}$ & $\begin{array}{l}\text { Complete } \\
\text { hemianopia }\end{array}$ \\
\hline 2 & $\mathrm{~F}$ & 43 & RE & $20 / 20$ & $\begin{array}{l}\text { Craniophary- } \\
\text { ngeoma }\end{array}$ & $\begin{array}{l}\text { Complete } \\
\text { hemianopia }\end{array}$ \\
\hline 3 & $\mathrm{~F}$ & 54 & LE & $20 / 20$ & Meningioma & $\begin{array}{l}\text { Complete } \\
\text { hemianopia }\end{array}$ \\
\hline \multirow[t]{2}{*}{4} & \multirow[t]{2}{*}{ M } & \multirow[t]{2}{*}{55} & RE & $20 / 30$ & \multirow[t]{2}{*}{ Adenoma } & $\begin{array}{l}\text { IT remaining with } \\
\mathrm{V} / 4 \mathrm{e}\end{array}$ \\
\hline & & & LE & $20 / 25$ & & $\begin{array}{l}\text { IT remaining with } \\
V / 4 \mathrm{e}\end{array}$ \\
\hline \multirow[t]{2}{*}{5} & \multirow[t]{2}{*}{ M } & \multirow[t]{2}{*}{48} & RE & $20 / 20$ & \multirow[t]{2}{*}{ Adenoma } & $\begin{array}{l}\text { IT remaining with } \\
V / 4 \mathrm{e} \text { and } \mathrm{I} / 4 \mathrm{e}\end{array}$ \\
\hline & & & LE & $20 / 20$ & & $\begin{array}{l}\text { IT remaining with } \\
V / 4 \mathrm{e}\end{array}$ \\
\hline \multirow[t]{2}{*}{6} & \multirow[t]{2}{*}{ M } & \multirow[t]{2}{*}{50} & RE & $20 / 30$ & \multirow[t]{2}{*}{ Adenoma } & $\begin{array}{l}\text { Complete } \\
\text { hemianopia }\end{array}$ \\
\hline & & & LE & $20 / 20$ & & $\begin{array}{l}\text { Complete } \\
\text { hemianopia }\end{array}$ \\
\hline 7 & $\mathrm{~F}$ & 61 & RE & $20 / 20$ & Adenoma & $\begin{array}{l}\text { IT remaining with } \\
V / 4 \mathrm{e} \text { and } \mathrm{I} / 4 \mathrm{e}\end{array}$ \\
\hline 8 & $\mathrm{~F}$ & 38 & OE & $20 / 20$ & Adenoma & $\begin{array}{l}\text { IT remaining with } \\
V / 4 \mathrm{e}\end{array}$ \\
\hline 9 & M & 72 & OE & $20 / 30$ & Adenoma & $\begin{array}{l}\text { IT remaining with } \\
\mathrm{V} / 4 \mathrm{e}\end{array}$ \\
\hline 10 & $\mathrm{~F}$ & 47 & RE & $20 / 20$ & Adenoma & $\begin{array}{l}\text { Complete } \\
\text { hemianopia }\end{array}$ \\
\hline 11 & $\mathrm{~F}$ & 34 & $\mathrm{LE}$ & $20 / 20$ & Adenoma & $\begin{array}{l}\text { IT remaining with } \\
V / 4 \mathrm{e} \text { and } \mathrm{I} / 4 \mathrm{e}\end{array}$ \\
\hline \multirow[t]{2}{*}{12} & \multirow[t]{2}{*}{ M } & \multirow[t]{2}{*}{21} & RE & $20 / 20$ & \multirow[t]{2}{*}{ Adenoma } & $\begin{array}{l}\text { IT remaining with } \\
V / 4 \mathrm{e}\end{array}$ \\
\hline & & & $\mathrm{LE}$ & $20 / 20$ & & $\begin{array}{l}\text { IT remaining with } \\
V / 4 \mathrm{e}\end{array}$ \\
\hline 13 & M & 18 & RE & $20 / 20$ & $\begin{array}{l}\text { Craniophary- } \\
\text { ngeoma }\end{array}$ & $\begin{array}{l}\text { IT remaining with } \\
\mathrm{V} / 4 \mathrm{e} \text { and } \mathrm{I} / 4 \mathrm{e}\end{array}$ \\
\hline 14 & $\mathrm{~F}$ & 20 & RE & $20 / 20$ & Adenoma & $\begin{array}{l}\text { Complete } \\
\text { hemianopia }\end{array}$ \\
\hline 15 & $\mathrm{~F}$ & 23 & RE & $20 / 20$ & Adenoma & $\begin{array}{l}\text { Complete } \\
\text { hemianopia }\end{array}$ \\
\hline 16 & $\mathrm{~F}$ & 49 & RE & $20 / 20$ & Adenoma & $\begin{array}{l}\text { IT remaining with } \\
\mathrm{V} / 4 \mathrm{e} \text { and } \mathrm{I} / 4 \mathrm{e}\end{array}$ \\
\hline
\end{tabular}

$M$, male; $F$, female; $L E$, left eye; $R E$, right eye; $V A$, visual acuity; IT, M, male; $F$, female;
inferior temporal.

RNFL thickness and how large the RNFL loss must be before it is detectable.

Optical coherence tomography is a high resolution technique that can create cross sectional images of the RNFL. RNFL loss has been documented by OCT in patients with optic nerve drusen, ${ }^{17}$ multiple sclerosis, ${ }^{18}$ and optic nerve trauma ${ }^{19}$ but most studies validating the ability of OCT to measure RNFL loss have been performed in patients with glaucoma..$^{7-11}$ Using OCT, several authors have found global mean RNFL in the superior and inferior quadrants in patients with glaucoma to be significantly lower than those of normal controls. ${ }^{7-11}$ Bowd et al compared the abilities of SLP, OCT, short wavelength automated perimetry, and frequency doubling technology perimetry to discriminate between healthy and glaucomatous eyes, and observed that the areas under the receiver operator characteristic curve were larger for the parameters of OCT than for those of other methods, indicating a better resolution of this instrument. We found the mean RNFL thickness values in each of the four quadrants, and in three superior and three inferior $30^{\circ}$ segments of glaucomatous eyes, to be significantly different from those of normal eyes. Nasal and temporal $30^{\circ}$ segments results were not reported. ${ }^{7}$ However Kanamori et al recently used OCT to compare the RNFL measurements of a large number of eyes with glaucoma to those of normal eyes using OCT. ${ }^{11}$ Significant differences in RNFL measurements were observed in the global average measurements as well as in

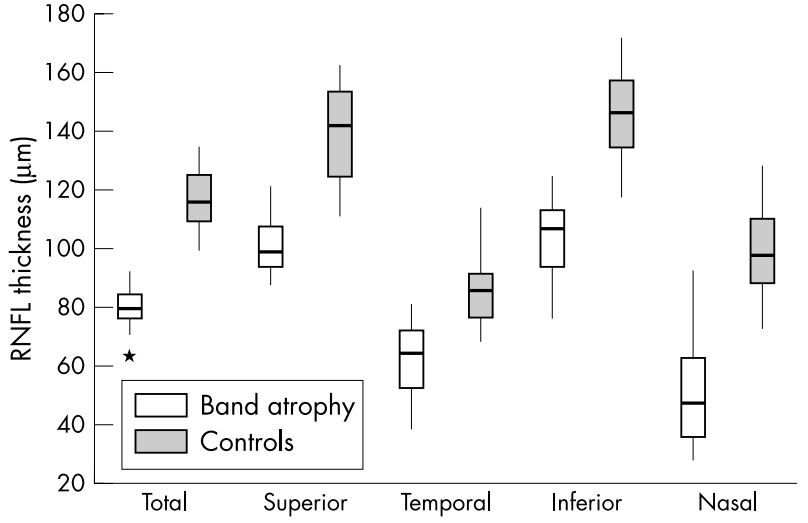

Figure 2 Box plot chart showing the distribution of retinal nerve fibre layer (RNFL) thickness measurements in each segment in both groups.

the superior and inferior quadrants, but not in the nasal and temporal quadrants. When $30^{\circ}$ segments around the optic disc were compared, no significant difference was observed in the temporal (9 and 8 o'clock) and nasal (4, 3, and 2 o'clock) segments, nor did Mok et $a^{20}$ find any significant difference between normal and glaucomatous eyes in the nasal and temporal quadrants. These findings could raise doubts about the sensitivity of OCT to identify RNFL abnormalities in the nasal and temporal regions of the disc.

The measurement of RNFL of eyes with BA, as in the current study, represents an important model in the evaluation of the ability of OCT to quantify RNFL loss in the nasal and temporal areas of the optic disc. As chiasmal decompression had already been obtained, the VF defects were severe and long standing, and as BA was observed on fundus examination in all cases, a severe or complete loss of RNFL in the temporal and nasal portions of the optic disc may be inferred. Our study showed that OCT was able to document RNFL loss in the nasal and temporal quadrants as well as in the nasal and temporal $30^{\circ}$ segments of the disc. This finding is in agreement with Midelberg and Yidegiligne' $\mathrm{s}^{17}$ automated quantitative histological analysis of a patient with BA evidencing an almost complete loss of nerve fibres in the nasal and temporal quadrants of the disc. The current study indicated a better potential of OCT when compared with the SLP (GDX). In a study conducted in 19 eyes with BA, we found that GDx was not able to identify RNFL loss in the temporal region, as there was no significant

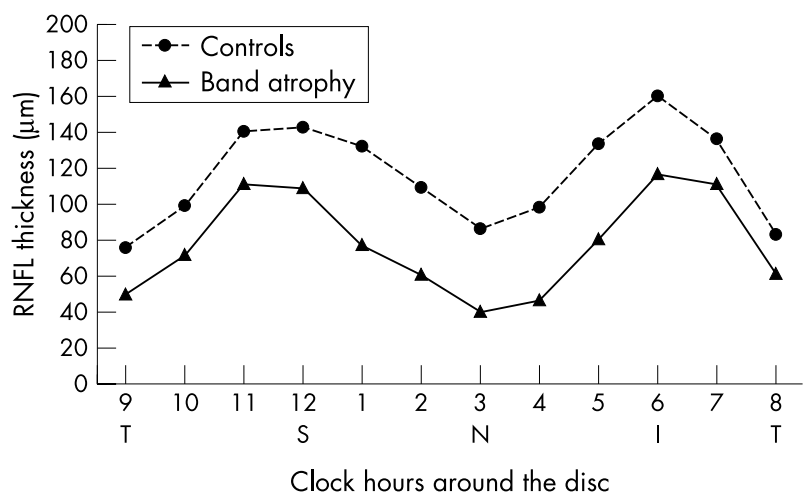

Figure 3 Plotting of the mean RNFL thickness per $30^{\circ}$ segment along the optic disc circumference (indicated as clock hours) in eyes with band atrophy and normal controls ( $T$, temporal; $\mathrm{S}$, superior; $\mathrm{N}$, nasal; I, inferior). 
difference in RNFL thickness measurements between patients with BA and controls. Furthermore, when we used the values provided by the GDx database, the deviation from normal analysis did not identify abnormalities in the temporal region in any of the patients, and was only able to identify abnormalities in the nasal region in two of the 19 eyes with $\mathrm{BA},{ }^{14}$ confirming the poor sensitivity of SLP to measure RNFL in the nasal and temporal segments of the disc observed by other authors. ${ }^{21} 22$

Our study shows that the RNFL was also reduced in the superior and inferior segments of the optic disc of eyes with BA. This is also in agreement with the study of Midelberg and Yidegiligne. ${ }^{13}$ These authors have documented that, although the loss of nerve fibres in eyes with BA occurs predominantly in the nasal and temporal segments, the superior and inferior areas of the optic disc lost approximately $50 \%$ of their fibres, as ganglion cell axons originating from the nasal retina also penetrate in the superior and inferior portions of the disc. ${ }^{17}$

This study, documenting the ability of OCT to measure RNFL in eyes with BA, is extremely important when studying neuro-ophthalmic conditions showing a predilection for RNFL loss in the nasal and temporal portions of the optic disc, such as chiasmal and optic tract compression, heredodegenerative diseases, and toxic, nutritional, compressive, and even inflammatory optic neuropathies. It is important, however, to keep in mind that the method still has limitations that must be taken into consideration when analysing individual cases. For example, Jones et $a l^{5}$ suggested that OCT underestimates RNFL thickness by an average of $37 \%$, and several studies have shown high interobserver and interindividual variation in the measurement of RNFL. ${ }^{23}{ }^{24}$ Furthermore, the high local variability observed may be accounted by the relatively small number of sampled points (100 A scans in the total circumference, resulting in only 8 or 9 points in each $30^{\circ}$ segment). ${ }^{4}{ }^{20}$ Future work with more recently developed software for this equipment, and using patients with a milder form of lesion, is therefore necessary in order to obtain a better understanding of the real value of OCT in evaluating RNFL for conditions other than glaucoma.

\section{Authors' affiliations}

M L R Monteiro, B C Leal, A A M Rosa, Division of Ophthalmology, Hospital das Clínicas of the University of São Paulo Medical School, São Paulo, Brazil

M D Bronstein, Division of Endocrinology, Hospital das Clínicas of the University of São Paulo Medical School, São Paulo, Brazil

Correspondence to: $\operatorname{Dr} M$ L R Monteiro, Av. Angélica 1757 conj. 61, 01227-200, São Paulo, SP, Brazil; mlrmonteiro@terra.com.br

Accepted 17 November 2003

\section{REFERENCES}

1 Huang D, Swanson EA, Lin CP, et al. Optical coherence tomography. Science 1991;254:1178-81

2 Schuman JS, Pedut-Kloizman T, Hertzmark E, et al. Reproducibility of nerve fiber layer thickness measurements using optical coherence tomography. Ophthalmology 1996;103:1889-98.

3 Baumann M, Gentile RC, Liebmann JM, et al. Reproducibility of retinal thickness measurements in normal eyes using optical coherence tomography. Ophthalmic Surg Lasers 1998;29:280-5.

4 Blumenthal EZ, Williams JM, Weinreb RN, et al. Reproducibility of nerve fiber layer thickness measurements by use of optical coherence tomography. Ophthalmology 2000;107:2278-82.

5 Jones AL, Sheen NJL, North RV, et al. The Humphrey optical coherence tomography scanner: quantitative analysis and reproducibility study of the normal human retinal nerve fibre layer. Br J Ophthalmol 2001;85:673-7.

6 Villain MA, Greenfield DS. Peripapillary nerve fiber layer thickness measurement reproducibility using optical coherence tomography. Ophthalmic Surg Lasers Imaging 2003;34:33-7.

7 Bowd C, Weinreb RN, Williams JM, et al. The retinal nerve fiber layer thickness in ocular hypertensive, normal, and glaucomatous eyes with optical coherence tomography. Arch Ophthalmol 2000;1 18:22-6.

8 Hoh ST, Greenfield DS, Mistlberger A, et al. Optical coherence tomography and scanning laser polarimetry in normal, ocular-hypertensive, and glaucomatous eyes. Am J Ophthalmol 2000;129:129-35.

9 Mistlberger A, Liebmann JM, Greenfield DS, et al. Heidelberg retina tomography and optical coherence tomography in normal, ocularhypertensive, and glaucomatous eyes. Ophthalmology 1999;106:2027-32.

10 Schuman JS, Hee MR, Puliafito CA, et al. Quantification of nerve fiber layer thickness in normal and glaucomatous eyes using optical coherence tomography. Arch Ophthalmol 1995;113:586-96.

11 Kanamori A, Nakamura M, Escano MFT, et al. Evaluation of the glaucomatous damage on retinal nerve fiber layer thickness measured by optical coherence tomography. Am J Ophthalmol 2003;135:513-20.

12 Unsöld R, Hoyt WF. Band atrophy of the optic nerve: the histology of temporal hemianopia. Arch Ophthalmol 1980;98:1637-8.

13 Midelberg FS, Yidegiligne HM. Axonal loss in band atrophy of the optic nerve in craniopharyngioma: a quantitative analysis. Can J Ophthalmol 1993;28:69-71

14 Monteiro MLR, Medeiros FA, Ostroscki MR. Quantitative analysis of axonal loss in band atrophy of the optic nerve using scanning laser polarimetry. Br J Ophthalmol 2003;87:32-7.

15 Hee MR, Izatt JA, Swanson EA, et al. Optical coherence tomography of the human retina. Arch Ophthalmol 1995;113:325-32.

16 Hoyt WF, Newman NM. The earliest observable defect in glaucoma? Lancet 1972;1:692-3.

17 Roh S, Noecker RJ, Schuman JS, et al. Effect of optic nerve head drusen on nerve fiber layer thickness. Ophthalmology 1998;105:878-85.

18 Parisi V, Manni G, Spadaro M, et al. Correlation between morphological and functional retinal impairment in multiple sclerosis patients. Invest Ophthalmol Vis Sci 1999;40:2520-7.

19 Medeiros FA, Moura FC, Vessani RM, et al. Axonal loss after traumatic optic neuropathy documented by optical coherence tomography. Am J Ophthalmol 2003; 135:406-8

20 Mok KH, Lee WWH, So KF. Retinal nerve fiber layer measurement by optical coherence tomography in glaucoma suspects with short-wavelength perimetry abnormalities. J Glaucoma 2003;12:45-9.

21 Kogure S, Chiba T, Kinoshita T, et al. Effect of artifacts on scanning laser polarimetry of retinal nerve fibre layer thickness measurement. Br J Ophthalmol 2000;86:1013-17.

22 Morgan JE, Waldock A, Jeffery G, et al. Retinal nerve fibre layer polarimetry: histological and clinical comparison. Br J Ophthalmol 1998;82:684-90.

23 Solimon MAE, Van der Berg TJTP, lamaeil AAA, et al. Retinal nerve fiber layer analysis: relationship between optical coherence tomography and red-free photography. Am J Ophthalmol 2002;133:187-95.

24 Carpineto P, Ciancaglini M, Zuppardi E, et al. Reliability of nerve fiber layer thickness measurements using optical coherence tomography in normal and glaucomatous eyes. Ophthalmology 2003;110:190-5. 